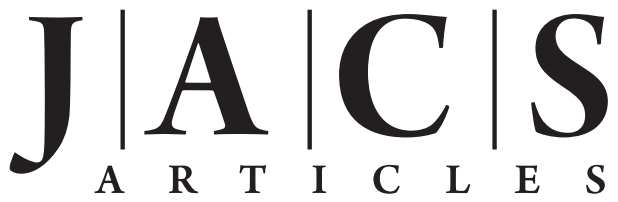

\title{
Size-Dependent Passivation Shell and Magnetic Properties in Antiferromagnetic/Ferrimagnetic Core/Shell MnO Nanoparticles
}

\author{
Alberto López-Ortega, ${ }^{\dagger}$ Dina Tobia, ${ }^{\ddagger}$ Elin Winkler, ${ }^{\ddagger}$ Igor V. Golosovsky, ${ }^{\S}$ \\ German Salazar-Alvarez, ${ }^{\dagger, \|}$ Sònia Estradé, ${ }^{\perp}$ Marta Estrader, ${ }^{,+\dagger}$ Jordi Sort, ${ }^{\uparrow, \#}$ \\ Miguel Angel González, ${ }^{@}$ Santiago Suriñach, ${ }^{*}$ Jordi Arbiol, ${ }^{\text {१, } \Delta}$ Francesca Peiró, ${ }^{\perp}$ \\ Roberto D. Zysler, ${ }^{\ddagger}$ Maria Dolors Baró," ${ }^{\#}$ and Josep Nogués ${ }^{\Uparrow, \dagger}$ \\ Centre d'Investigació en Nanociència i Nanotecnologia (ICN-CSIC), Campus Universitat \\ Autònoma de Barcelona, E-08193 Bellaterra, Spain, Centro Atómico Bariloche, \\ CNEA-CONICET, 8400 S.C. de Bariloche, Río Negro, Argentina, St. Petersburg Nuclear Physics \\ Institute, 188300 Gatchina, St. Petersburg, Russia, Department of Materials and Environmental \\ Chemistry, Stockholm University, S-10691 Stockholm, Sweden, MIND-IN2UB, Departament \\ d'Electrònica, Universitat de Barcelona, Martí i Franquès 1, E-08028 Barcelona, Spain, \\ Institució Catalana de Recerca i Estudis Avançats (ICREA), Barcelona, Spain, Departament de \\ Física, Universitat Autònoma de Barcelona, E-08193 Bellaterra, Spain, Institut Laue Langevin, \\ 6 rue Jules Horowitz, BP 156, F-38042 Grenoble, France, and Institut de Ciència de Materials \\ de Barcelona (CSIC), Campus Universitat Autònoma de Barcelona, E-08193 Bellaterra, Spain
}

Received March 15, 2010; E-mail: marta.estrader.icn@uab.cat

\begin{abstract}
The magnetic properties of bimagnetic core/shell nanoparticles consisting of an antiferromagnetic $\mathrm{MnO}$ core and a ferrimagnetic passivation shell have been investigated. It is found that the phase of the passivation shell $\left(\gamma-\mathrm{Mn}_{2} \mathrm{O}_{3}\right.$ or $\left.\mathrm{Mn}_{3} \mathrm{O}_{4}\right)$ depends on the size of the nanoparticles. Structural and magnetic characterizations concur that while the smallest nanoparticles have a predominantly $\gamma-\mathrm{Mn}_{2} \mathrm{O}_{3}$ shell, larger ones have increasing amounts of $\mathrm{Mn}_{3} \mathrm{O}_{4}$. A considerable enhancement of the Néel temperature, $T_{\mathrm{N}}$, and the magnetic anisotropy of the $\mathrm{MnO}$ core for decreasing core sizes has been observed. The size reduction also leads to other phenomena such as persistent magnetic moment in $\mathrm{MnO}$ up to high temperatures and an unusual temperature behavior of the magnetic domains.
\end{abstract}

\section{Introduction}

Magnetic nanoparticles are attracting a great deal of interest from both fundamental and applied points of view. ${ }^{1-4}$ Magnetic recording media, catalysis, ferrofluids, pigments, hyperthermia, medical diagnostics, and drug delivery are among the increasing number of applications of magnetic nanoparticles. Due to their small size and, particularly, their large surface-to-volume ratio magnetic nanoparticles exhibit properties different from those of their bulk counterparts, which can be exploited to obtain new functionalities. Although ferromagnetic (FM) and ferrimagnetic (FiM) nanoparticles have been extensively studied, antiferro-

To whom correspondence should be addressed: E-mail:

ICN-CSIC, Campus Universitat Autònoma de Barcelona.

$\div$ CNEA-CONICET.

$\S$ St. Petersburg Nuclear Physics Institute.

"Stockholm University.

${ }^{\perp}$ Universitat de Barcelona.

II ICREA, Universitat Autònoma de Barcelona.

\# Departament de Física, Universitat Autònoma de Barcelona.

@ Institut Laue Langevin.

${ }^{\Delta}$ Institut de Ciència de Materials de Barcelona (CSIC), Campus Universitat Autònoma de Barcelona.

(1) Lu, A. H.; Salabas, E. L.; Schuth, F. Angew. Chem., Int. Ed. 2007, 46, 1222-1244.

(2) Tartaj, P.; Morales, M. P.; Veintemillas-Verdager, S.; GonzálezCarreño, T.; Serna, C. J. J. Phys. D 2003, 36, R182-R197.

(3) Batlle, X.; Labarta, A. J. Phys. D 2002, 35, R15-R42.

(4) Willard, M. A.; Kurihara, L. K.; Carpenter, E. E.; Calvin, S.; Harris, V. G. Int. Mater. Rev. 2004, 49, 125-170. magnetic (AFM) nanoparticles have been far less investigated and are thus less understood. ${ }^{5}$ Nevertheless, antiferromagnetic nanoparticles and nanostructures play an important role in spintronic devices ${ }^{6}$ and have been proposed as means to overcome the superparamagnetic limit in recording media or to enhance the coercivity of ferromagnets. ${ }^{7,8}$ Although finite size effects in antiferromagnetic nanoparticles are similar to those of FM or FiM materials (e.g., superparamagnetism or reduced blocking temperatures), some effects are specific to AFMs (e.g., the appearance of finite magnetization due to sublattice uncompensation). ${ }^{1-5}$

Special types of magnetic nanoparticles are core/shell nanoparticles. Although in most cases the shell serves just for protection purposes, the study of bimagnetic nanoparticles, where both the shell and the core are magnetic, is steadily increasing. ${ }^{6,9-30}$ In fact, the shell properties and exchange coupling between the core and the shell open new degrees of

(5) Mørup, S.; Madsen, D. E.; Frandsen, C.; Bahl, C. R. H.; Hansen, M. F. J. Phys.: Condens. Matter 2007, 19, 213202.

(6) Nogués, J.; Sort, J.; Langlais, V.; Skumryev, V.; Suriñach, S.; Muñoz, J. S.; Baró, M. D. Phys. Rep. 2005, 422, 65-117.

(7) Skumryev, V.; Stoyanov, S.; Zhang, Y.; Hadjipanayis, G.; Givord, D.; Nogués, J. Nature (London) 2003, 423, 850-853.

(8) (a) Sort, J.; Suriñach, S.; Muñoz, J. S.; Baró, M. D.; Nogués, J.; Chouteau, G.; Skumryev, V.; Hadjipanayis, G. C. Phys. Rev. B 2002, 65, 174420. (b) Sort, J.; Nogués, J.; Suriñach, S.; Muñoz, J. S.; Baró, M. D.; Chappel, E.; Dupont, F.; Chonteau, G. Appl. Phys. Lett. 2001, $79,1142-1144$. 
freedom to tailor the overall properties of the nanoparticles, leading to novel applications (such as enhanced coercivity and energy products, tunable blocking temperatures, improved electromagneticradiationabsorption, andhyperthermiatreatment)., Core/shell nanoparticles with a FM (or FiM) core and a AFM (or FiM) shell have been widely investigated. ${ }^{6,9-11}$ Recently, "inverse" core/shell nanoparticles, with AFM cores and FiM or spin-glass shells, have been synthesized, leading to a number of novel magnetic properties. ${ }^{34-46}$ In particular, the magnetic properties of inverse core/shell nanoparticles based on the

(9) Iglesias, O.; Labarta, A.; Batlle, X. J. Nanosci. Nanotechnol. 2008, 8, $2761-2780$

(10) Liu, W.; Zhong, W.; Du, Y. W. J. Nanosci. Nanotechnol. 2008, 8, 2781-2792.

(11) Casavola, M.; Buonsanti, R.; Caputo, G.; Cozzoli, P. D. Eur. J. Inorg. Chem. 2008, 837-854.

(12) Eftaxias, E.; Trohidou, K. N. Phys. Rev. B 2005, 71, 134406.

(13) Salazar-Alvarez, G.; Sort, J.; Uheida, A.; Muhammed, M.; Suriñach, S.; Baró, M. D.; Nogués, J. J. Mater. Chem. 2007, 17, 322-328.

(14) Liu, X. S.; Gu, B. X.; Zhong, W.; Jiang, H. Y.; Du, Y. W. Appl. Phys. A: Mater. Sci. Process. 2003, 77, 673-676.

(15) Zeng, H.; Sun, S.; Li, J.; Wang, Z. L.; Liu, J. P. Appl. Phys. Lett. 2004, 85, 792-794.

(16) Figuerola, A.; Fiore, A.; Di Corato, R.; Falqui, A.; Giannini, C.; Micotti, E.; Lascialfari, A.; Corti, M.; Cingolani, R.; Pellegrino, T.; Cozzoli, P. D.; Manna, L. J. Am. Chem. Soc. 2008, 130, 1477-1487.

(17) Nogués, J.; Skumryev, V.; Sort, J.; Stoyanov, S.; Givord, D. Phys. Rev. Lett. 2006, 97, 157203.

(18) Masala, O.; Seshadri, R. J. Am. Chem. Soc. 2005, 127, 9354-9355.

(19) Seo, W. S.; Jo, H. H.; Lee, K.; Kim, B.; Oh, S. J.; Park, J. T. Angew. Chem., Int. Ed. 2004, 43, 1115-1117.

(20) Riveiro, J. M.; De Toro, J. A.; Andrés, J. P.; González, J. A.; Muñoz, T.; Goff, J. P. Appl. Phys. Lett. 2005, 86, 172503.

(21) Morel, R.; Brenac, A.; Portemont, C. J. Appl. Phys. 2004, 95, $3757-$ 3760.

(22) Dobrynin, A. N.; Ievlev, D. N.; Temst, K.; Lievens, P.; Margueritat, J.; Gonzalo, J.; Afonso, C. N.; Zhou, C. Q.; Vantomme, A.; Piscopiello, E.; Van Tendeloo, G. Appl. Phys. Lett. 2005, 87, 012501.

(23) Del Bianco, L.; Fiorani, D.; Testa, A. M.; Bonetti, E.; Savini, L.; Signoretti, L. Phys. Rev. B 2002, 66, 174418.

(24) Si, P. Z.; Li, D.; Choi, C. J.; Li, Y. B.; Geng, D. Y.; Zhang, Z. D. Solid State Commun. 2007, 142, 723-726.

(25) Johnston-Peck, A. C.; Wang, J. W.; Tracy, J. B. ACS Nano 2009, 3 , $1077-1084$

(26) Zhou, S. M.; Imhoff, D.; Yu-Zhang, K.; Leprince-Wang, Y. Appl. Phys. A: Mater. Sci. Process. 2005, 85, 115-118.

(27) Tracy, J. B.; Weiss, D. N.; Dinega, D. P.; Bawendi, M. G. Phys. Rev. $B$ 2005, 72, 064404 .

(28) Luna, C.; Morales, M. D.; Serna, C. J.; Vazquez, M. Nanotechnology 2004, 15, S293-S297.

(29) Inderhees, S. E.; Borchers, J. A.; Green, K. S.; Kim, M. S.; Sun, S.; Strycker, G. L.; Aronson, M. S. Phys. Rev. Lett. 2008, 101, 117202.

(30) Gangopadhyay, S.; Hadjipanayis, G. C.; Sorensen, C. M.; Klabunde, K. J. IEEE Trans. Magn. 1993, 29, 2602-2607.

(31) Zeng, H.; Li, J.; Wang, Z. L.; Liu, J. P.; Sun, S. H. Nano Lett. 2004, 4, 187-190.

(32) Lu, B.; Huang, H.; Dong, X. L.; Zhang, X. F.; Lei, J. O.; Sun, J. P.; Dong, C. J. Appl. Phys. 2008, 104, 114313.

(33) Habib, A. B.; Ondeck, C. L.; Chaudhary, P.; Bockstaller, M. R McHenry, M. E. J. Appl. Phys. 2008, 103, 07A307.

(34) Salazar-Alvarez, G.; Sort, J.; Suriñach, S.; Baró, M. D.; Nogués, J. J. Am. Chem. Soc. 2007, 129, 9102-9108.

(35) Golosovsky, I. V.; Salazar-Alvarez, G.; López-Ortega, A.; González, M. A.; Sort, J.; Estrader, M.; Suriñach, S.; Baró, M. D.; Nogués, J. Phys. Rev. Lett. 2009, 102, 247201.

(36) Berkowitz, A. E.; Rodriguez, G. F.; Hong, J. I.; An, K.; Hyeon, T.; Agarwal, N.; Smith, D. J.; Fullerton, E. E. Phys. Rev. B 2008, 77, 024403 .

(37) Berkowitz, A. E.; Rodriguez, G. F.; Hong, J. I.; An, K.; Hyeon, T.; Agarwal, N.; Smith, D. J.; Fullerton, E. E. J. Phys. D 2008, 41, 134007.

(38) Djerdj, I.; Ačcon, D.; Jagličić, Z.; Niederberger, M. J. Phys. Chem. C 2007, 111, 3614-3623.

(39) Wang, Z. H.; Geng, D. Y.; Hu, W. J.; Ren, W. J.; Zhang, Z. D. J. Appl. Phys. 2009, 105, 07A315.

(40) Si, P. Z.; Li, D.; Lee, J. W.; Choi, C. J.; Zhang, Z. D.; Geng, D.Y. U. Appl. Phys. Lett. 2005, 87, 133122.

(41) Zhou, S. M.; Shi, L.; Yang, H. P.; Wang, Y.; He, L. F.; Zhao, J. Y. Appl. Phys. Lett. 2008, 93, 182509. passivation of AFMMnOnanoparticles have been investigated. ${ }^{34-38,40}$ These materials exhibit novel properties at low temperatures ${ }^{34-37,40}$ such as very large exchange bias and coercivity with a nonmonotonic dependence on the core diameter ${ }^{34}$ and spontaneous magnetization and ferrimagnetic order above the Curie temperature of the shell. ${ }^{35-37}$ However, in these nanoparticles, although the shell material is usually identified as $\mathrm{Mn}_{3} \mathrm{O}_{4}, 34,36-38,40$ it has been recently shown that $\gamma-\mathrm{Mn}_{2} \mathrm{O}_{3}$ can also be formed as a result of $\mathrm{MnO}$ passivation. ${ }^{35}$

In this article we present the study of $\mathrm{MnO}(\mathrm{AFM})-\gamma-\mathrm{Mn}_{2} \mathrm{O}_{3}$ or $\mathrm{Mn}_{3} \mathrm{O}_{4}$ (FiM) core/shell nanoparticles by diverse techniques (i.e., neutron diffraction, TEM, EELS, ac susceptibility, magnetometry, and electron spin resonance). The magnetic and structural results indicate that the structure of the passivation shell of the $\mathrm{MnO}$ nanoparticles depends on the core size, being primarily $\gamma-\mathrm{Mn}_{2} \mathrm{O}_{3}$ for small cores and progressively transforming to $\mathrm{Mn}_{3} \mathrm{O}_{4}$ for larger cores. Moreover, the core/shell nanoparticles exhibit a range of interesting properties such as large coercivities, exchange bias or enhanced anisotropy, and Néel temperatures of the core.

\section{Experimental Section}

Nanoparticles with different sizes were obtained by adding 7.5 mmol of manganese(II) acetylacetonate ( $\mathrm{Mn}(\mathrm{acac})_{2}$ purum, Aldrich) and $7.5 \mathrm{mmol}$ of 1,2-hexadecanediol (HDD 90\%, Aldrich) to 150 $\mathrm{mL}$ of dibenzyl ether (DBE analytical, Aldrich) in a $250 \mathrm{~mL}$ roundbottomed flask under an inert argon atmosphere followed by the addition of a surfactant, oleylamine (OA 70\%, Aldrich), in a surfactant-to-metal ratio, $[\mathrm{S}]:[\mathrm{M}](\mathrm{mol} / \mathrm{mol})$, from 1 to 40 . The solution was mechanically stirred and heated, at a heating rate of $8-10{ }^{\circ} \mathrm{C} / \mathrm{min}$, to a given temperature, in the range of $190-240{ }^{\circ} \mathrm{C}$ with reflux and a residence time of 30-60 min. The flask was removed from the heating source, cooled in argon to $80{ }^{\circ} \mathrm{C}$, and subsequently exposed to air and cooled to room temperature to obtain the passivated shell. The particles were washed from the reaction media by subsequent steps of precipitation under ethanol, centrifugation, and redispersion in hexane. The synthesis parameters are summarized in Table 1.

Neutron diffraction measurements were carried out at different temperatures, in the range $10-250 \mathrm{~K}$, at the D20 diffractometer of the Institute Laue-Langevin with a neutron wavelength of 1.305 $\AA$ A. ${ }^{47}$ Typical neutron diffraction patterns are shown in Figure 1 and Figure S1 (Supporting Information). All diffraction patterns were analyzed using the FullProf code ${ }^{48}$ based on the known crystal structures of $\mathrm{MnO}$ and $\gamma-\mathrm{Mn}_{2} \mathrm{O}_{3}$ (or $\mathrm{Mn}_{3} \mathrm{O}_{4}$ ). This method, in contrast with the so-called "matching mode", provides more stable refinement (see curve $\mathrm{c}$ in Figure 1 and Figure S1) in the present case due to the strong overlapping of the principal peaks and the presence of small parasitic reflections (see arrows in Figure 1). Note that the rather large diffuse background is due to the remains of surfactants used in the synthesis.

Transmission electron microscopy (TEM) images were obtained using a JEM-2010 instrument with a $\mathrm{LaB}_{6}$ filament and a JEM-

(42) Markovich, V.; Fita, I.; Wisniewski, A.; Puzniak, R.; Mogilyansky, D.; Titelman, L.; Vradman, L.; Herskowitz, M.; Gorodetsky, G. Phys. Rev. B 2008, 77, 054410.

(43) Kavich, D. W.; Dickerson, J. H.; Mahajan, S. V.; Hasan, S. A.; Park, J. H. Phys. Rev. B 2008, 78, 174414.

(44) Shin, J. M.; Anisur, R. M.; Ko, M. K.; Im, G. H.; Lee, J. H.; Lee, I. S. Angew. Chem., Int. Ed. 2009, 48, 321-324.

(45) An, K.; Kwon, S. G.; Park, M.; Na, H. B.; Baik, S. I.; Yu, J. H.; Kim, D.; Son, J. S.; Kim, Y. W.; Song, I. C.; Moon, W. K.; Park, H. M.; Hyeon, T. Nano Lett. 2008, 8, 4252-4258.

(46) Yun, B. K.; Koo, Y. S.; Jung, J. H. J. Magn. 2009, 14, 147-149.

(47) Hansen, T. C.; Henry, P. F.; Fischer, H. E.; Torregrossa, J.; Convert, P. Meas. Sci. Technol. 2008, 19, 034001

(48) Rodriguez-Carvajal, J. Phys. B 1993, 192, 55-69. (http://www.ill.eu/ sites/fullprof). 
Table 1. Summary of the Synthesis Conditions and the Structural Parameters Obtained from Neutron Diffraction and TEM Analyses

\begin{tabular}{|c|c|c|c|c|c|c|c|c|c|c|c|}
\hline \multirow[b]{2}{*}{ sample } & \multicolumn{4}{|c|}{ synthesis params } & \multicolumn{4}{|c|}{ neutron analysis } & \multicolumn{3}{|c|}{ TEM } \\
\hline & {$[\mathrm{S}]:[\mathrm{M}](\mathrm{mol} / \mathrm{mol})$} & {$\left[\mathrm{Mn}^{2+}\right](\mathrm{mol} / \mathrm{mL})$} & $T\left({ }^{\circ} \mathrm{C}\right)$ & $t(\min )$ & $D_{\mathrm{MnO}}(\mathrm{nm})$ & $a_{\mathrm{MnO}}(\AA)$ & $D_{\text {shell }}(\mathrm{nm})$ & $\overline{t_{\text {shell }}(\mathrm{nm})}$ & $D_{\text {tot }}(\mathrm{nm})$ & $D_{\mathrm{MnO}}(\mathrm{nm})$ & $t_{\text {shell }}(\mathrm{nm})$ \\
\hline M1 & 1.03 & 0.05 & 240 & 30 & $19(2)$ & $4.4200(8)$ & $2.8(3)$ & 1.5 & $25(6)$ & 21 & $4-5$ \\
\hline M3 & 4.1 & 0.05 & 220 & 30 & $15.7(5)$ & $4.4431(6)$ & $5.0(2)$ & 0.5 & $13(5)$ & 10 & $3-4$ \\
\hline M4 & 20 & 0.04 & 190 & 30 & $4.7(3)$ & $4.374(2)$ & $4.9(3)$ & 2 & $5(1)$ & 3 & $2-3$ \\
\hline
\end{tabular}

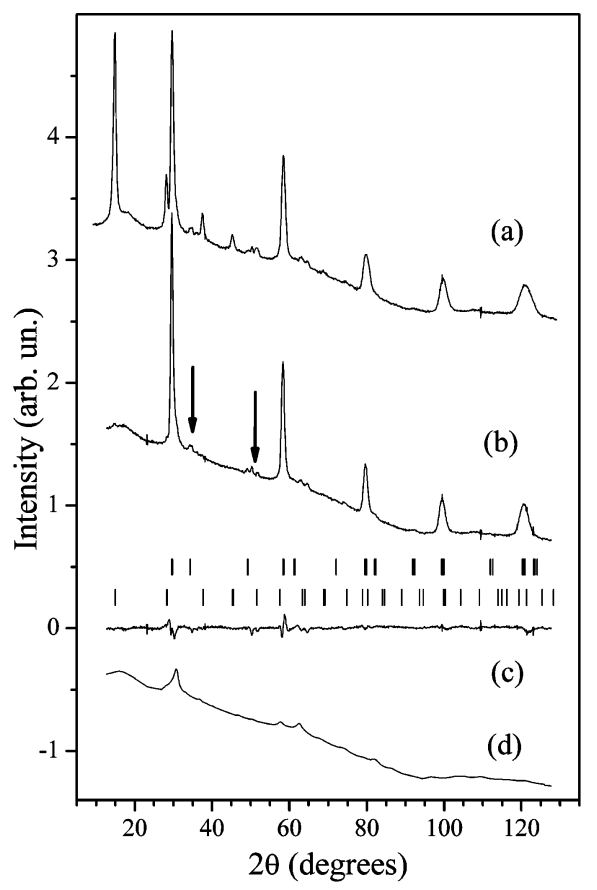

Figure 1. Neutron diffraction patterns measured at (a) $20 \mathrm{~K}$ and (b) 250 $\mathrm{K}$ for sample M2. The small reflections shown by the arrows are due to the cryostat and the sample holder. (c) Difference pattern (calculated observed) at $250 \mathrm{~K}$. (d) Calculated pattern from the shell $\gamma-\mathrm{Mn}_{2} \mathrm{O}_{3}-\mathrm{Mn}_{3} \mathrm{O}_{4}$, showing its contribution to the total patterns (a) and (b). The stripes mark the positions of the Bragg reflections from the $\mathrm{MnO}$ core: upper and lower rows correspond to the magnetic and nuclear reflections, respectively.

(49) Kurata, H.; Colliex, C. Phys. Rev. B 1993, 48, 2102-2108.

(50) Egerton, R. F. Electron Energy-Loss Spectroscopy in the Electron Microscope, 2nd ed.; Kluwer: Dordrecht, The Netherlands, 1996.

(51) Estradé, S.; Arbiol, J.; Peiró, F.; Abad, Ll.; Laukhin, V.; Balcells, L1.; Martı́nez, B. Appl. Phys. Lett. 2007, 91, 252503.

(52) Estradé, S.; Arbiol, J.; Peiró, F.; Infante, I. C.; Sánchez, F.; Fontcuberta, J.; de la Peña, F.; Walls, M.; Colliex, C. Appl. Phys. Lett. 2008, 93, 112505.

(53) Estradé, S.; Rebled, J. M.; Arbiol, J.; Peiró, F.; Infante, I. C.; Herranz, G.; Sánchez, F.; Fontcuberta, J.; Córdoba, R.; Mendis, B. G.; Bleloch, A. L. Appl. Phys. Lett. 2009, 95, 072507.

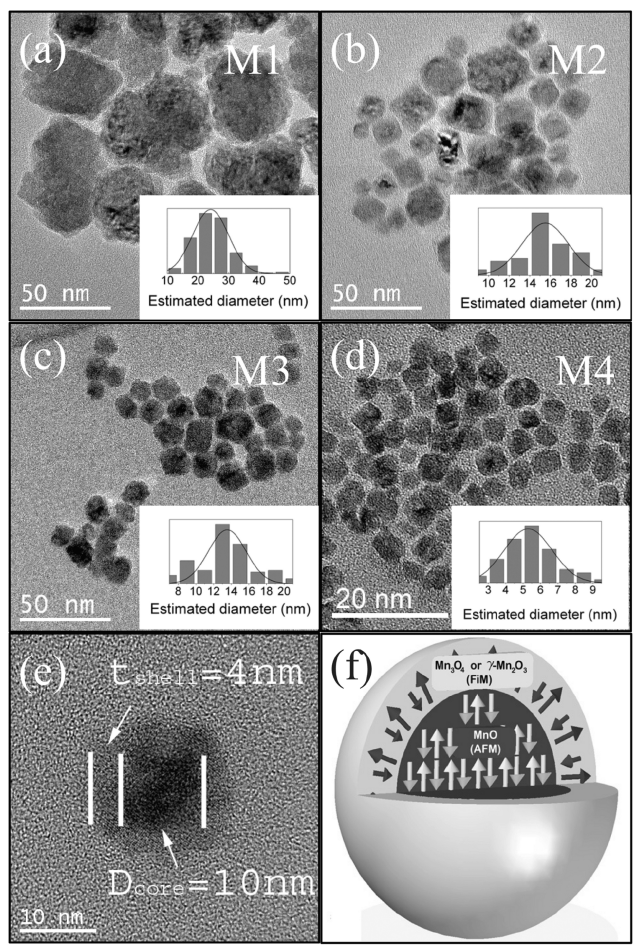

Figure 2. Transmission electron micrographs of samples (a) M1, (b) M2, (c) M3 and (d) M4 (note the different magnification). Shown in the respective insets are the corresponding particle size distributions with a fit to a log-norm function. (e) High-resolution image of an M2 nanoparticle. (f) Schematic representation of the morphological and magnetic structures of the nanoparticles.

exceedingly large, leading to a weaker EELS signal and consequently to larger errors. Note that several particles were measured for each sample.

dc magnetic measurements were carried out on loosely packed powdered samples using a superconducting quantum interference device (SQUID, Quantum Design) magnetometer with $70 \mathrm{kOe}$ maximum field. The magnetization measurements were carried out at $50 \mathrm{Oe}$. The hysteresis loops were measured at $T=10 \mathrm{~K}$ after field cooling in $H_{\mathrm{FC}}=20 \mathrm{kOe}$ from $T=200 \mathrm{~K}$.

The ac susceptibility measurements were performed at different frequencies, between $10 \mathrm{~Hz}$ and $10 \mathrm{kHz}$, applying an ac field of 10 Oe using physical properties measurement system (PPMS, Quantum Design) equipment.

The temperature dependence of the electron spin resonance (ESR) spectra were recorded by a Bruker ESP300 spectrometer at $9.5 \mathrm{GHz}$. The parameters that characterize the resonance signal are the resonance field $H_{\mathrm{r}}$, the line width $\Delta H$, and the spectrum intensity, $I_{\mathrm{ESR}}$. From the $H_{\mathrm{r}}$ value, at room temperature, we derived the gyromagnetic factor $g$ through the resonance condition $h v=g \mu_{\mathrm{B}} H_{\mathrm{r}}$, where $h$ and $\mu_{\mathrm{B}}$ are Planck's constant and Bohr magneton, respectively. The line width is a measurement of the spin-relaxation mechanism, and it is measured as the distance between the peaks in the derivative of the absorption spectrum. The spectrum intensity 

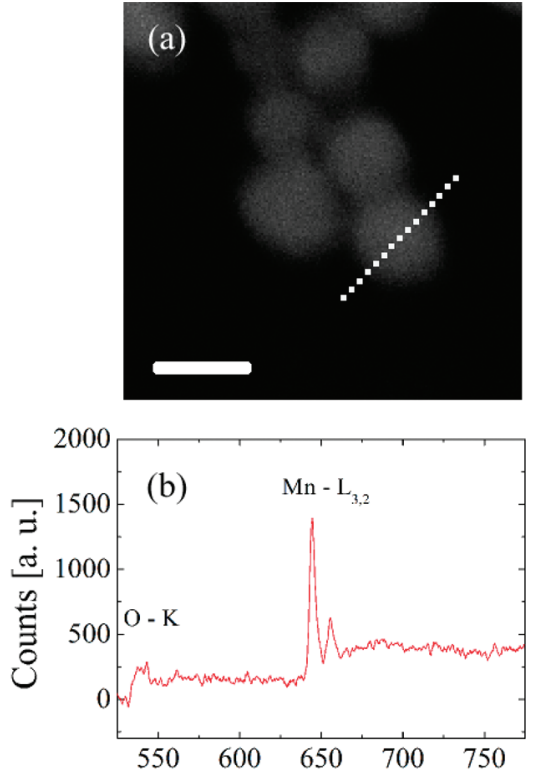

Electron Energy Loss [eV]

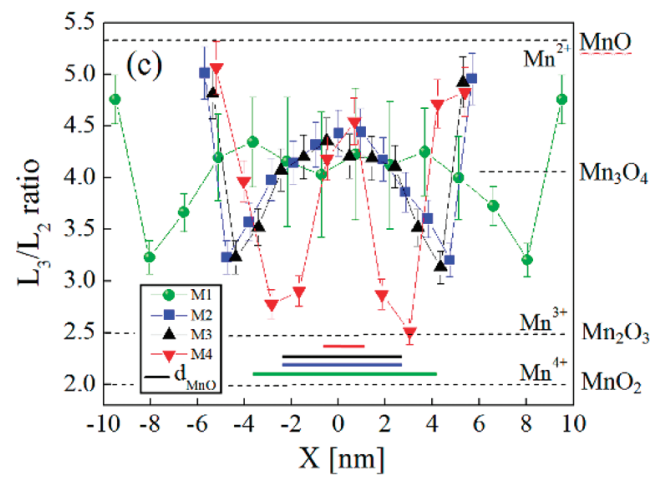

Figure 3. (a) High-angle annular dark field (HAADF) image of M4 nanoparticles, where the approximate positions at which spectra were taken are indicated by dots. (b) Typical background-subtracted EEL spectrum of the shell part for M4. (c) $M n-L_{3} / L_{2}$ intensity ratio along the diameter of the M1-M4 nanoparticles. The lines joining the data points are guides to the eye. The dotted lines in the figure are the expected $\mathrm{L}_{3} / \mathrm{L}_{2}$ ratios for $\mathrm{Mn}^{2+}$, $\mathrm{Mn}^{3+}$, and $\mathrm{Mn}^{4+}$ ions, respectively. ${ }^{49,54}$ The thick solid lines in (c) indicate the diameter of the core as estimated from the position dependence of the $\mathrm{Mn}-\mathrm{L}_{3} / \mathrm{L}_{2}$ intensity ratio.

is the area under the absorption curve and is proportional to the concentration of resonant magnetic ions.

\section{Results and Discussion}

Structural and Morphological Characterization. As can be seen from the high-temperature neutron diffraction (shown in curve b in Figure 1 and Figure S1 for samples M2 and M4, respectively), the $\mathrm{MnO}$ core exhibits the expected rock salt crystal structure. However, although samples M1-M3 show a stoichiometric structure, sample M4 has defects on the Mn sites with a $0.74(2)$ occupancy ratio. ${ }^{35}$ Concerning the shell structure sample, M4 does not exhibit the expected hausmannite, $\mathrm{Mn}_{3} \mathrm{O}_{4}$, structure $^{34,36,37}$ but a spinel type tetragonal $\gamma-\mathrm{Mn}_{2} \mathrm{O}_{3}$ structure. ${ }^{35,56}$ For samples M1-M3 the neutron diffraction signal is overwhelmed by the $\mathrm{MnO}$ spectrum (see curve $\mathrm{d}$ in Figure 1); thus, it is impossible to distinguish between the $\gamma-\mathrm{Mn}_{2} \mathrm{O}_{3}$ and the $\mathrm{Mn}_{3} \mathrm{O}_{4}$ structures for the shell.

(56) Goodenough, J. B.; Loeb, A. L. Phys. Rev. 1955, 98, 391-408.
All the studied samples show a similar temperature dependence of the lattice parameter for $\mathrm{MnO}$, which displays a distinct feature around $125 \mathrm{~K}$ : i.e., at the MnO Néel temperature. ${ }^{35}$ This is similar to the behavior observed in the bulk, ${ }^{57}$ implying a rather well structured $\mathrm{MnO}$ core. Interestingly, the lattice parameter of $\mathrm{MnO}$ is contracted with respect to the bulk and becomes smaller as the core size decreases (see Table 1), in contrast with most oxide nanoparticle systems which show a lattice expansion for reduced particle sizes. ${ }^{58}$ The smaller lattice parameter is likely caused by the presence of a large number of defects, since no stresses due to the outer passivation layer were detected. In most of the samples the contribution from the $\mathrm{MnO}$ core dominates in the diffraction patterns; therefore, the lattice parameters of the shell were determined with lower accuracy. We did not observe any essential difference in the temperature dependence of the lattice parameters of the different samples, which were evaluated as $a=5.844(5) \AA$ and $c=$ 9.13(1) $\AA$.

From the fitting of the different patterns at diverse temperatures the structural and magnetic characteristic sizes and structures can be readily obtained. The diffraction peak broadening comprises two contributions, which have different $q$ dependencies: internal stresses (i.e., microstrains) and crystallite size effect. The profile analysis of the diffraction patterns shows that the stresses are negligible within experimental error. Therefore, from the peak broadening one can easily obtain the volume-averaged crystallite size and the magnetic domain size.

The volume-averaged diameter of the $\mathrm{MnO}$ core, $D_{\mathrm{MnO}}$, and the characteristic sizes of ferrimagnetic nanoparticles forming the shell, $D_{\text {shell, }}$ are shown in Table 1 . Interestingly, while $D_{\mathrm{MnO}}$ ranges from 5 to $19 \mathrm{~nm}$ on adjusting the synthesis conditions, $D_{\text {shell }}$ remains rather constant at around 3-5 $\mathrm{nm}$. Note that due to the limited statistics it is not possible to directly evaluate any anisotropy in the particle shape, from the peak profile analysis. However, from the core/shell volume ratios obtained from the fit, indirect information can be inferred. Taking into account the volume ratios and the measured diameters of the cores and assuming a uniform core/shell structure, the corresponding averaged effective thickness of the shell, $t_{\text {shell }}$, can be estimated (see Table 1). Hence, on comparison of the effective shell thickness and the shell crystallite sizes obtained from the profile refinement it can be concluded that the nanoparticles forming the ferrimagnetic shell layer are strongly anisotropic (e.g., pancakelike).

In order to confirm this feature, TEM images of the samples were obtained, and the results are summarized in Table 1. All the samples exhibit a clear core/shell structure with average overall particle sizes, $D_{\text {tot }}$, of 25(6) nm for M1, 15(5) nm for $\mathrm{M} 2,13(5) \mathrm{nm}$ for M3, and 5(1) nm for M4 (where the value in parentheses is the log-norm standard deviation; see insets in Figure 2). The shell thicknesses, $t_{\text {shell, }}$ remain rather homogeneous, in the range of $\sim 2-5 \mathrm{~nm}$ (see Table 1 ). Note that the shells are more difficult to image, since each individual particle needs a specific imaging tilt to allow the shell to be clearly observed (see Figure 2e). Thus, the statistics are not sufficient to evaluate standard deviations and only estimates are given. The values of the core diameter obtained from TEM and neutron diffraction follow a similar trend, where the small discrepancies probably arise from the different averaging methods (number

(57) Morosin, B. Phys. Rev. B 1970, 1, 236-243.

(58) Zheng, X. G.; Kubozono, H.; Yamada, H.; Kato, K.; Ishiwata, Y.; Xu, C. N. Nat. Nanotechnol. 2008, 3, 724-726. 
(59) Allen, T. Particle Size Measurements, 5th ed.; Chapman \& Hall: London, 1997.

(60) Chen, D. X.; Sanchez, A.; Taboada, E.; Roig, A.; Sun, N.; Gu, H. C. J. Appl. Phys. 2009, 105, 083924.

(55) Pan, Y.; Sader, K.; Powell, J. J.; Bleloch, A.; Gass, M.; Trinick, J.; Warley, A.; Brydson, A. L.; Brown, A. J. Struct. Biol. 2009, 166, $22-31$.

(61) Roth, W. L. Phys. Rev. 1958, 110, 1333-1341.

(62) Jensen, G. B.; Nielsen, O. V. J. Phys. C 1974, 7, 409-424.

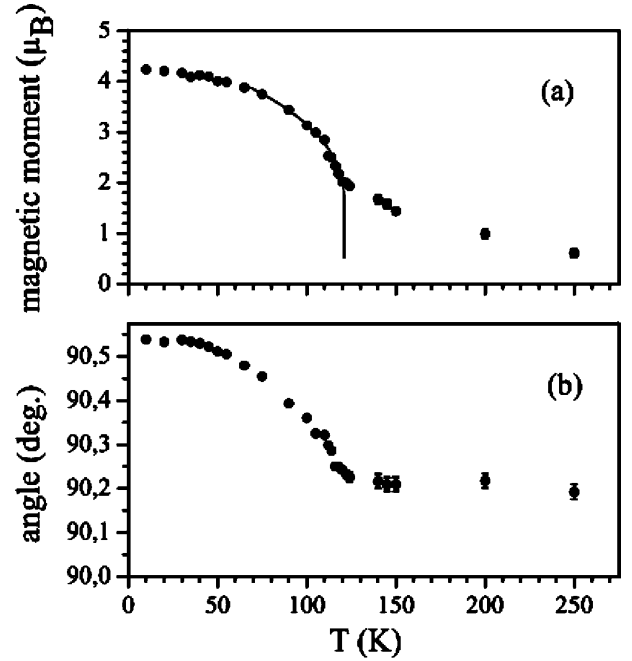

Figure 4. (a) Temperature dependence of the magnetic moment/ion in the $\mathrm{MnO}$ core for sample M2. The solid lines correspond to a fit with a power law. (b) Temperature dependence of the angle of trigonal distortion.

Table 2. Summary of the Effective Néel Temperature and Sublattice Magnetization for the MnO Core, $M_{\mathrm{MnO}}$

\begin{tabular}{ccl}
\hline sample & $T_{\mathrm{N}}(\mathrm{K})$ & $M_{\text {Mno }}\left(\mu_{\mathrm{B}}\right)$ \\
\hline M1 & $123(1)$ & $4.25(7)$ \\
M2 & $120.9(2)$ & $4.21(2)$ \\
M3 & $126.0(2)$ & $3.83(8)$ \\
M4 & $139(10)$ & $4.3(5)$ \\
\end{tabular}

as well as in "restricted geometry", 63,64 taking into account the trigonal distortion due to magnetostriction ${ }^{65}$ shown in Figure $4 \mathrm{~b}$. As expected, the value of the saturated magnetic moment appears smaller than the $5 \mu_{\mathrm{B}}$ for the free $\mathrm{Mn}^{2+}$ ion (see Table 2 ). This is a known effect and is readily explained by the spin disordering at the core surface (i.e., at the interface in our case), ${ }^{63}$ although some spin canting in the core ${ }^{66}$ or partial oxidation of the $\mathrm{Mn}$ ions cannot be ruled out. Assuming the temperature dependence of the magnetic moment follows a power law in the temperature range of the main drop of magnetic moment (note the "tail" in $m$ for higher temperatures), the effective Néel temperature of the $\mathrm{MnO}$ cores was evaluated as 120.9(2) $\mathrm{K}$ for M2 (Figure 4a). Similar analyses for the other samples lead to $T_{\mathrm{N}}=120.9(2)-139(10)$ for M1-M4 (see Figure 5 and Table 2 ). Note that a $T_{\mathrm{N}}$ enhancement has been also observed in $\mathrm{MnO}$ confined in different porous templates ${ }^{63,64}$ (see Figure 5) and in other manganese oxides, ${ }^{67,68}$ although it is not present in $\mathrm{MnF}_{2}$ films. ${ }^{69}$ The origin of this effect has been proposed to arise from size and surface effects, where the broken symmetry at the surface and the concomitant local disorder may lead to (i) enhancement of the exchange interaction between surface

(63) Golosovsky, I. V.; Mirebeau, I.; André, G.; Kurdyukov, D. A.; Kumzerov, Y. A.; Vakhrushev, S. B. Phys. Rev. Lett. 2001, 86, 57831786.

(64) Golosovsky, I. V.; Mirebeau, I.; Sakhnenko, V. P.; Kurdyukov, D. A.; Kumzerov, Y. A. Phys. Rev. B 2005, 72, 144409.

(65) Lines, M. E.; Jones, E. D. Phys. Rev. 1965, 113, A1313.

(66) Theil Kuhn, L.; Bojesen, A.; Timmermann, L.; Meedom Nielsen, M.; Mørup, S. J. Phys.: Condens. Matter 2002, 14, 13551-13567.

(67) Tang, Z. X.; Sorensen, C. M.; Klabunde, K. J.; Hadjipanayis, G. C. Phys. Rev. Lett. 1991, 67, 3602-3605.

(68) Yang, A.; Chinnasamy, C. N.; Greneche, J. M.; Chen, Y. J.; Yoon, S. D.; Chen, Z. H.; Hsu, K. L.; Cai, Z. H.; Ziemer, K.; Vittoria, C.; Harris, V. G. Nanotechnology 2009, 20, 185704.

(69) Golosovsky, I. V.; Sokolov, N. S.; Gukasov, A.; Bataille, A.; Boehm, M.; Nogués, J. J. Magn. Magn. Mater. 2010, 322, 664-667. 


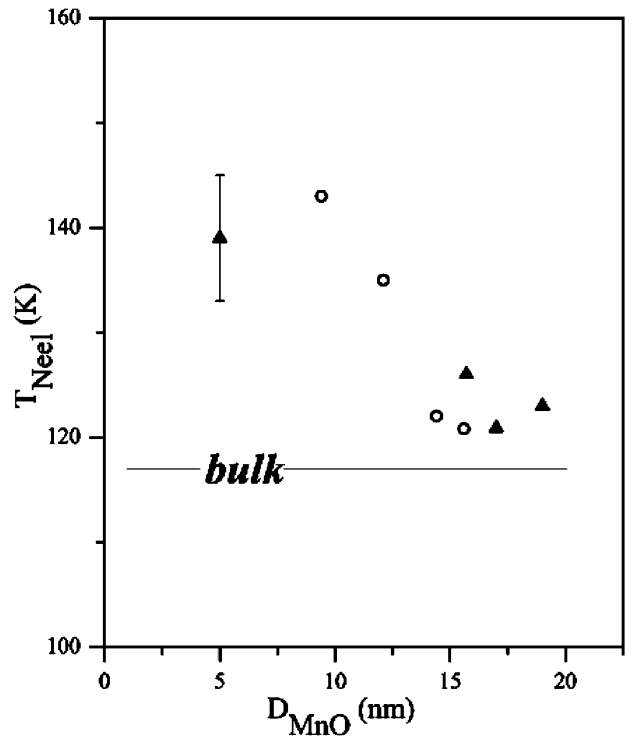

Figure 5. Dependence of the Néel temperature, effective $T_{\mathrm{N}}$, for the $\mathrm{MnO}$ cores in the core/shell nanoparticles (triangles) and $\mathrm{MnO}$ nanoparticles embedded within porous glass (circles) ${ }^{73}$ on the core size $D_{\mathrm{MnO}}$.

atoms with respect to bulk exchange interactions ${ }^{70}$ and (ii) variations in the crystal field resulting in high-spin-low-spin transitions $^{71}$ and/or the appearance of new degrees of freedom which interact with the AFM order parameter. ${ }^{64}$ Moreover, other effects such as the observed size dependence of the lattice parameter may also play a role. ${ }^{72}$

Remarkably, as can be seen in Figure 4a for sample M2, with a thin passivation shell, the observed antiferromagnetic order in $\mathrm{MnO}$ does not vanish at the Néel temperature and persists up to room temperature, where the sublattice magnetization of $\mathrm{MnO}$ exhibits a "tail" up to high temperatures rather than vanishing above $T_{\mathrm{N}}$.

Interestingly, the averaged diameter of the magnetic domains in the $\mathrm{MnO}$ core calculated from the broadening of the antiferromagnetic peak appears to be significantly smaller than the core diameter: $-6.7(5)$ vs 17.0(5) nm (M2) and 9(1) vs 19(2) $\mathrm{nm}$ (M1). Note that due to peak overlapping the magnetic size could only be determined for samples M1 and M2. Similar domain size effects were observed in $\mathrm{MnO}$ nanoparticles embedded within different porous media. ${ }^{63,64}$ In Figure 6 the temperature dependence of the full width at half-maximum (fwhm) of the $\mathrm{MnO}(1 / 2,1 / 2,1 / 2)$ magnetic reflection and volume average domain diameter are shown for M2. It is seen that the diameter drastically changes with temperature, reaching a minimum at temperatures well above $T_{\mathrm{N}}=120.9 \mathrm{~K}$. The results resemble a fragmentation of the magnetic domains observed in first-order transitions. However, due to size effects there should be a continuous magnetic transition, ${ }^{74,75}$ in contrast to the bulk first-order transition. ${ }^{61}$ In fact, the magnetic domain fragmentation may explain the large "tail" in the temperature dependence

(70) Wesselinowa, J. M. J. Magn. Magn. Mater. 2010, 322, 234-237.

(71) Morales, M. A.; Skomski, R.; Fritz, S.; Shelburne, G.; Shiled, J. E.; Yin, M.; O'Brien, S.; Leslie-Pelecky, D. L. Phys. Rev. B 2007, 75, 134423.

(72) Kantor, I.; Dubrovinsky, L.; McCammon, C.; Dubrovinskaia, L.; Goncharenko, I.; Kantor, A.; Kuznetsov, A.; Crichton, W. Phase Trans. 2007, 80, 1151-1167.

(73) Golosovsky, I. V. Private communication.

(74) Imry, Y. Phys. Rev. B 1980, 21, 2042-2043.

(75) Challa, M. S. S.; Landau, D. P.; Binder, K. Phys. Rev. B 1986, 34, 1841-1852.

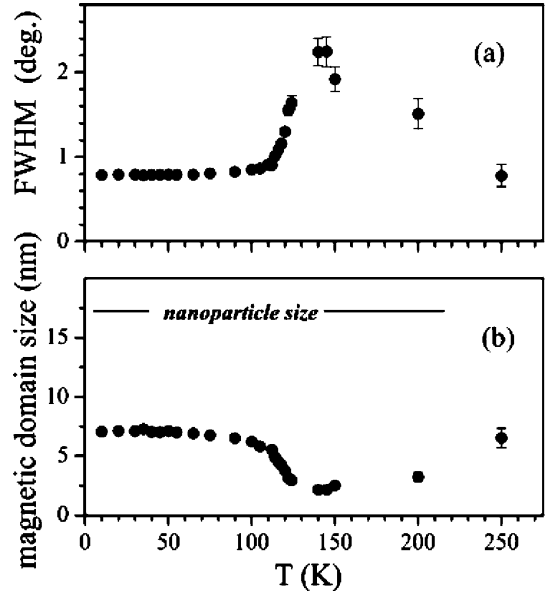

Figure 6. (a) Temperature dependence of the fwhm of the $\mathrm{MnO}(1 / 2,1 /$ $2,1 / 2$ ) magnetic reflection for sample M2. (b) Size (averaged diameter) of the magnetic domain deduced from the peak broadening.

of the magnetic moment (Figure 4a), since smaller $\mathrm{MnO}$ entities have larger $T_{\mathrm{N}}$ values. Although some of these effects could be partially explained by the concomitant particle size distribution, they are exceedingly large to arise solely from this effect.

Shown in Figure 7 are the hysteresis loops of the samples at $10 \mathrm{~K}$ after field cooling in $20 \mathrm{kOe}$ from $200 \mathrm{~K}$. The saturation magnetization, $M_{\mathrm{S}}$ (obtained by using the total mass), is different for each sample. Using the TEM values for the particle size and the shell thickness and assuming that the $\mathrm{MnO}$ core does not contribute to $M_{\mathrm{S}}$, we can estimate the saturation magnetization of the shell. Despite the crude approximations the $M_{\mathrm{S}}$ values are rather consistent with $M_{\mathrm{S}} \approx 32.0-37.7 \mathrm{emu} / \mathrm{g}$ for M1-M3 and are slightly smaller for $\mathrm{M} 4, M_{\mathrm{S}} \approx 27 \mathrm{emu} / \mathrm{g}$. These results are consistent with saturation magnetization for bulk $\mathrm{Mn}_{3} \mathrm{O}_{4}\left(M_{\mathrm{S}}\right.$ $\approx 38 \mathrm{emu} / \mathrm{g})^{76}$ and $\gamma-\mathrm{Mn}_{2} \mathrm{O}_{3}$ nanoparticles $\left(M_{\mathrm{S}} \approx 28 \mathrm{emu} / \mathrm{g}\right){ }^{77}$

All the loops exhibit a large coercivity, $H_{\mathrm{C}}$ (see Figure 7 ), which is consistent with the rather large anisotropy of the $\gamma-\mathrm{Mn}_{2} \mathrm{O}_{3}$ or $\mathrm{Mn}_{3} \mathrm{O}_{4}$ phases. ${ }^{77-80}$ Moreover, the coercivity is influenced by the coupling to the AFM core, ${ }^{6}$ where the smallest core gives rise to the largest coercivity, in agreement with previous reports. ${ }^{34}$ Moreover, as expected, ${ }^{34,36,37}$ all the samples exhibit a loop shift along the field axis (exchange bias, $H_{\mathrm{E}}$ ), evidencing the exchange coupling between the AFM core and the FiM shell. ${ }^{6}$ The nonmonotonic dependence of $H_{\mathrm{E}}$ with the $\mathrm{MnO}$ core size (see Figure 7) is consistent with earlier results in the same system, ${ }^{34}$ characterized by its inverse, $T_{\mathrm{N}}>T_{\mathrm{C}}$, magnetic structure. ${ }^{81,82}$

The temperature dependence of the FC and ZFC magnetization measured with $H=50$ Oe (Figure 8) reveals that all the samples exhibit their main magnetic features below $T \approx 50 \mathrm{~K}$, consistent with the known Curie temperature, $T_{\mathrm{C}}=39$ and 42 $\mathrm{K}$, of the $\gamma-\mathrm{Mn}_{2} \mathrm{O}_{3}$ and $\mathrm{Mn}_{3} \mathrm{O}_{4}$ phases, respectively. ${ }^{77,80,84}$ Thus, the magnetization is largely dominated by the ferrimagnetic

(76) Jacobs, I. S. J. Phys. Chem. Solids 1959, 11, 1-11.

(77) Kim, S. H.; Choi, B. J.; Lee, G. H.; Oh, S. J.; Kim, B.; Choi, H. C.; Park, J.; Chang, Y. J. Korean Phys. Soc. 2005, 46, 941-944.

(78) Dwight, K.; Menyuk, N. Phys. Rev. 1960, 119, 1470-1479.

(79) Du, C. S.; Yun, J. D.; Dumas, R. K.; Yuan, X. Y.; Liu, K.; Browning, N. D.; Pan, N. Acta Mater. 2008, 56, 3516-3522.

(80) Tackett, R.; Lawes, G.; Melot, B. C.; Grossman, M.; Toberer, E. S.; Seshadri, R. Phys. Rev. B 2007, 76, 024409.

(81) Cai, J. W.; Liu, K.; Chien, C. L. Phys. Rev. B 1999, 60, 72-75.

(82) Nogués, J.; Schuller, I. K. J. Magn. Magn. Mater. 1999, 192, $203-$ 232

(84) Srinivasan, G.; Seehra, M. S. Phys. Rev. B 1983, 28, 1-7. 


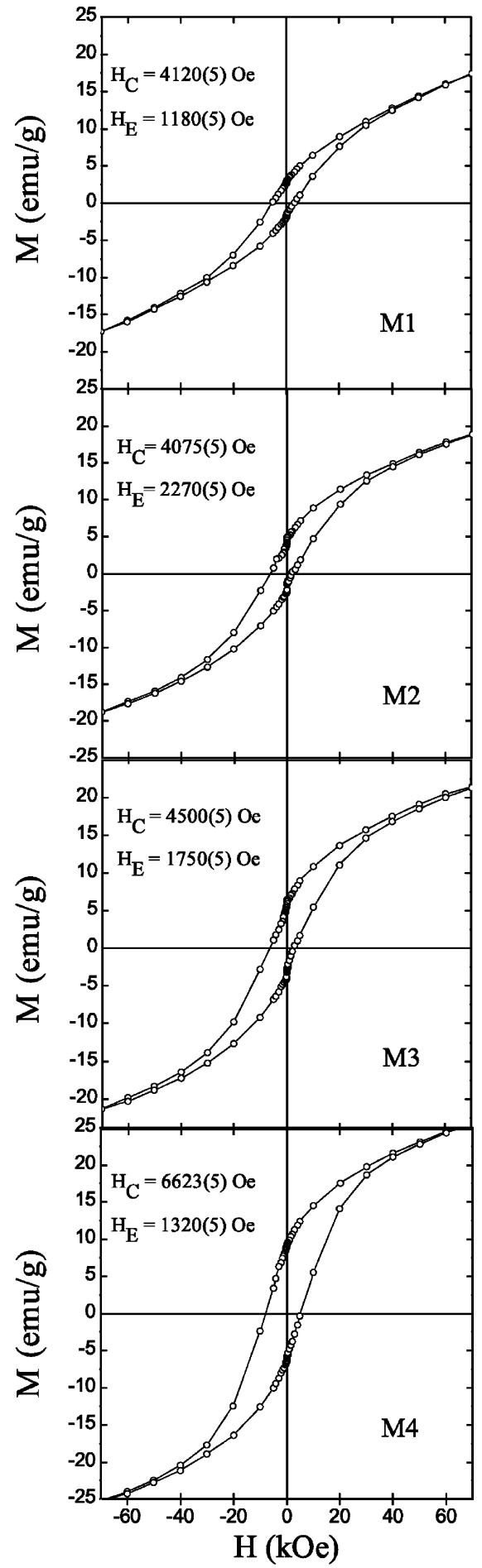

Figure 7. Hysteresis loops for samples $\mathrm{M} 1-\mathrm{M} 4$ at $T=10 \mathrm{~K}$ after field cooling from $T=200 \mathrm{~K}$ in $H_{\mathrm{FC}}=20 \mathrm{kOe}$. The values of $H_{\mathrm{E}}$ and $H_{\mathrm{C}}$ are indicated in the respective panels. counterpart. Interestingly, it can be seen that the ZFC branch of samples M1-M3 exhibits fine structure below $T_{\mathrm{C}} \approx 42 \mathrm{~K}$ and there is a hump at $T \approx 33 \mathrm{~K}$ and a second anomaly at $T \approx$ $20 \mathrm{~K}$. In contrast, for sample M4 both the FC and ZFC curves are featureless.

To gain further insight into the nature of the low-temperature anomalies, ac susceptibility measurements were carried out. Figure 9 shows the real $\left(\chi^{\prime}\right)$ and imaginary $\left(\chi^{\prime \prime}\right)$ components of the ac susceptibility measured at different frequencies from 10 $\mathrm{Hz}$ to $10 \mathrm{kHz}$ on applying an ac field of $10 \mathrm{Oe}$. The larger

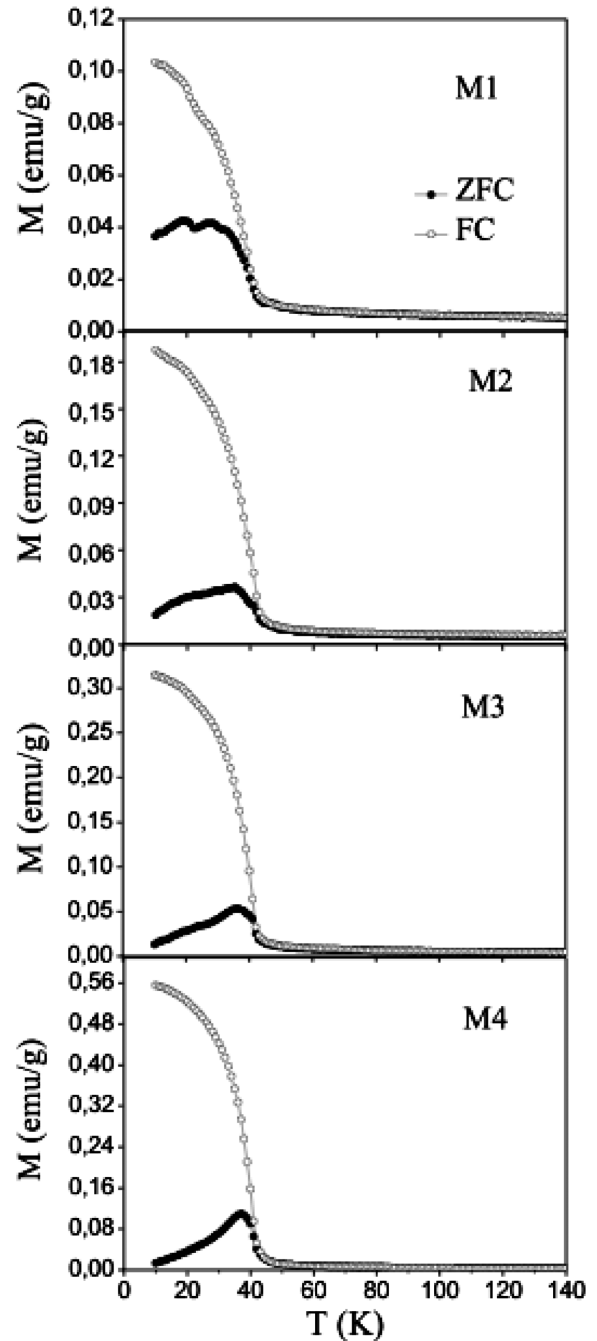

Figure 8. Temperature dependence of the field cooled (FC) and zero field cooled (ZFC) magnetizations for samples M1-M4 measured in $H=50$ Oe.

nanoparticles present anomalies in $\chi^{\prime}$ and $\chi^{\prime \prime}$ at 41, 36, and 20 $\mathrm{K}$. These anomalies are frequency independent, implying that they are thermodynamic transitions rather than blocking temperatures. The transition temperatures are consistent with the reported $T_{\mathrm{C}}=42 \mathrm{~K}$ and the reorientation transitions of $\mathrm{Mn}_{3} \mathrm{O}_{4}$ $\left(T_{\mathrm{RO}}=39 \mathrm{~K}\right.$ and $\left.T_{\mathrm{RO}} *=33 \mathrm{~K}\right) .{ }^{62}$ For M4, instead, the ac susceptibility exhibits a single transition, as was also observed in the $M(T)$ dc magnetization curve. This result is not consistent with the magnetic behavior of the $\mathrm{Mn}_{3} \mathrm{O}_{4}$ phase, in agreement with neutron diffraction and EELS results which indicate that the M4 shell is solely formed by $\gamma-\mathrm{Mn}_{2} \mathrm{O}_{3}$. The experimental results suggest the following picture for the systems: the nanoparticles present a core/shell structure with AFM MnO core and a FiM shell that changes its composition $\left(\gamma-\mathrm{Mn}_{2} \mathrm{O}_{3}\right.$ and/or $\mathrm{Mn}_{3} \mathrm{O}_{4}$ ) depending on the nanoparticle size, as shown schematically in Figure $2 \mathrm{f}$.

Electron Spin Resonance. In order to quantify the core/shell composition, we also performed an ESR spectroscopy study. Figure 10 shows representative ESR spectra for temperatures above and below $T_{\mathrm{N}}$ for M1-M4. Above $T_{\mathrm{N}}$ the spectra exhibit two resonance lines, one narrow and one broad, both centered at around $H_{\mathrm{r}}=3370 \mathrm{Oe}$. This corresponds to a gyromagnetic factor of $g \approx 2.00$, which is consistent with the values reported 


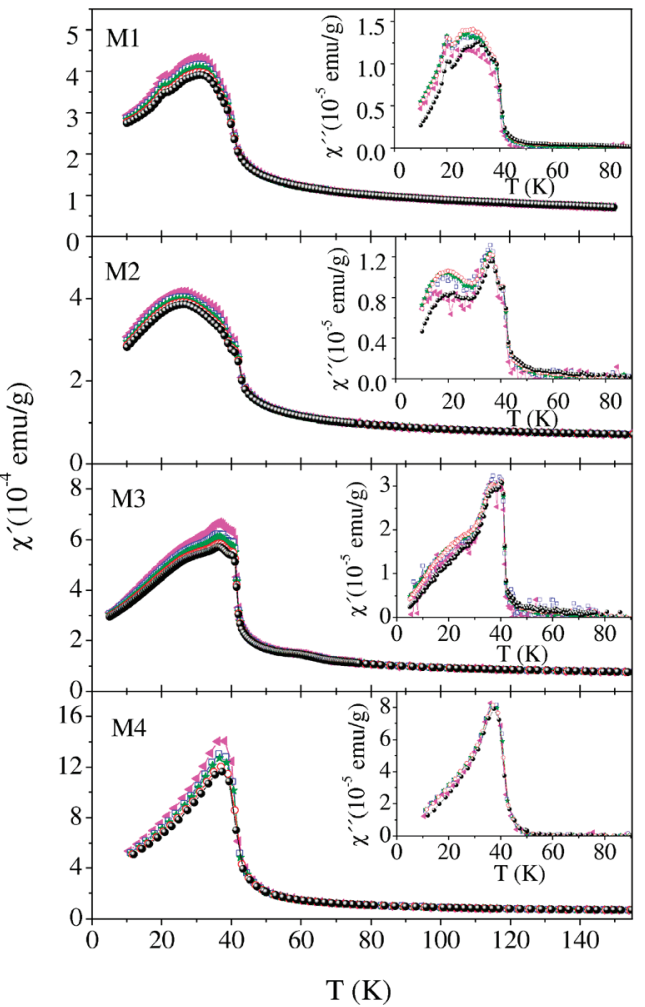

Figure 9. Temperature dependence of in-phase $\left(\chi^{\prime}\right)$ and out-of-phase $\left(\chi^{\prime \prime}\right)$ ac susceptibilities for samples M1-M4 measured at different frequencies:

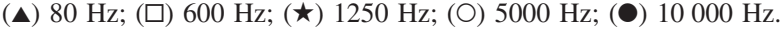

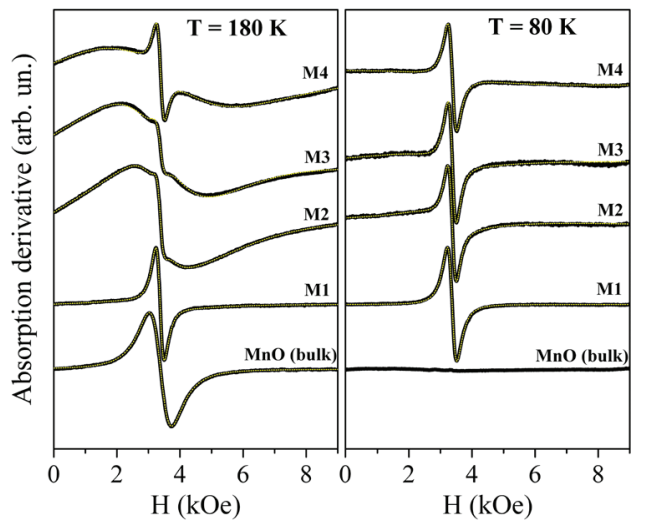

Figure 10. ESR spectra for the four samples $\mathrm{M} 1-\mathrm{M} 4$ and bulk $\mathrm{MnO}$ above and below $T_{\mathrm{N}}$. The dotted line corresponds to the fitting curve (color on line). Note that for sample M1 the main ESR line corresponds to the shell resonance which remains below $T_{\mathrm{N}}$. in the literature $\left(g=2.02-2.00\right.$ for $\mathrm{Mn}_{3} \mathrm{O}_{4}{ }^{83-85}$ and $g=$ 1.997-2.001 for $\left.\mathrm{MnO}^{86-88}\right)$. When the temperature decreases, $\Delta H$ increases for the broad signal, and at $T \approx 120 \mathrm{~K}$ it is no longer detected. The narrow signal, instead, is observed in the entire measured temperature range and presents a nonmonotonic temperature evolution.

It is known that below the AFM transition temperature, because of the large anisotropy and exchange fields present,

(83) Seehra, M. S.; Srinivasan, G. J. Appl. Phys. 1982, 52, 8345-8347.

(85) Winkler, E.; Zysler, R. D.; Fiorani, D. Phys. Rev. B 2004, 70, 174406.

(86) Dormann, E.; Jaccarino, V. Phys. Lett. 1974, 48A, 81-82.

(87) Ferrante, R. F.; Wilkerson, J. L.; Graham, W. R. M.; Weltne, W., Jr. J. Chem. Phys. 1977, 67, 5904-5913.

(88) Golosovsky, I. V.; Arcon, D.; Jaglicic, Z.; Cevc, P.; Sakhnenko, V. P.; Kurdyukov, D. A.; Kumzerov, Y. A. Phys. Rev. B 2005, 72, 144410.

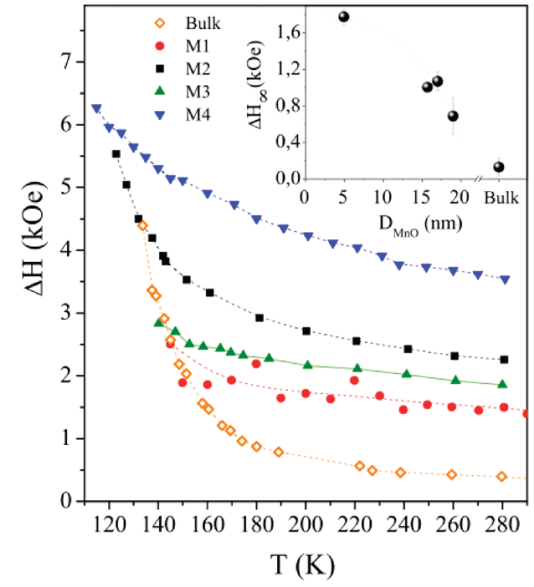

Figure 11. Temperature dependence of the ESR line width, $\Delta H$, corresponding to the $\mathrm{MnO}$ core phase for samples M1-M4. For comparison, the parameters corresponding to the $\mathrm{MnO}$ bulk phase are also included. The inset shows the evolution of $\Delta H_{\infty}$ with the $\mathrm{MnO}$ core size.

the spin equilibrium state changes and the AFM resonance modes cannot be excited. Therefore, $T_{\mathrm{N}}$ is usually determined by the disappearance of the ESR spectrum. ${ }^{89}$ This behavior is reproduced by the AFM MnO pure phase, as was reported by several authors. ${ }^{86-88}$ This fact allowed us to identify the broad ESR resonance as coming from the AFM MnO (core) phase, while the narrow line is assigned to the shell phase, as will be explained later.

In order to quantify and extract reliable ESR parameters, we fitted the total spectral signal with two Lorentzian lines centered at $g \approx 2$. Figure 10 shows the ESR spectra with the corresponding fitting curve. For comparison the resonance signal of the $\mathrm{MnO}$ bulk sample is also included. Observe that all the samples present the same qualitative behavior: two resonance lines for $T>T_{\mathrm{N}}$, where the relative intensities are different for each M1-M4 system, and a narrow resonance for $T<T_{\mathrm{N}}$. Apart from the main narrow resonance, below $T \approx 40 \mathrm{~K}$ a second broad low-field resonance was also observed in a small temperature range. This line shifts toward zero field, and at $T$ $\approx 27 \mathrm{~K}$ it is no longer detected. A low-field resonance with identical temperature and field behavior is present in the $\mathrm{Mn}_{3} \mathrm{O}_{4}$ pure oxide ${ }^{84,85}$ This resonance is attributed to the FiM resonance of ordered magnetic domains at different orientation respect to the magnetic field. ${ }^{84}$

The temperature dependence of $\Delta H$ obtained from the fitting curves for the core and the shell components are shown in Figures 11 and 12a. The ESR parameters for bulk $\mathrm{MnO}$ (Figure 11) and $\mathrm{Mn}_{3} \mathrm{O}_{4}$ (inset Figure 12a) are also included as reference. From Figure 11 it is manifested that the line width of the $\mathrm{MnO}$ core decreases when the size of the particle increases. At room temperature $\Delta H \approx 3500$ Oe for M4 and approaches the bulk value $\Delta H \approx 400$ Oe for larger sizes. The line width depends on the magnetization relaxation mechanism. In the paramagnetic range the following dependence was established: $\Delta H=$ $C /(T \chi(T)) \Delta H_{\infty},{ }^{86,90,91}$ where $C$ is the Curie constant and $\Delta H_{\infty}$ is the value reached by $\Delta H$ at high temperature. Assuming that the susceptibility follows a Curie-Weiss dependence with a Curie-Weiss temperature $\Theta \approx-600 \mathrm{~K}$, we have estimated

(89) Huber, D. L.; Alejandro, G.; Caneiro, A.; Causa, M. T.; Prado, F.; Tovar, M.; Oseroff, S. B. Phys. Rev. B 1999, 60, 12155-12161.

(90) Causa, M. T.; et al. Phys. Rev. B 1998, 58, 3233-3239.

(91) Huber, D. L. J. Phys. Chem. Solids 1971, 32, 2145-2149.

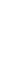
(20)

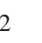

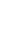
47

\footnotetext{
J. AM. CHEM. SOC. - VOL. XXX, NO. $X X, X X X X$
} 


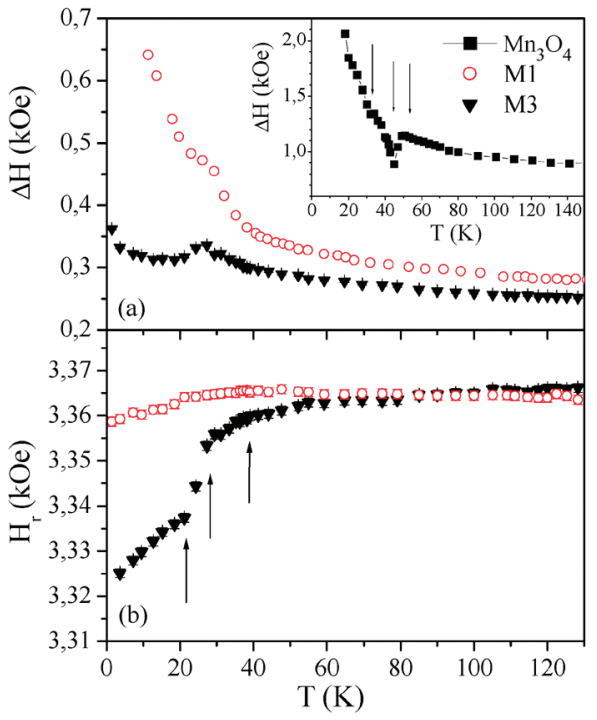

Figure 12. (a) Temperature dependence of the ESR line width, $\Delta H$, corresponding to the $\mathrm{Mn}_{3} \mathrm{O}_{4}$ phase of the samples $\mathrm{M} 1$ and $\mathrm{M} 3$. For comparison, the measured parameters of the isolated $\mathrm{Mn}_{3} \mathrm{O}_{4}$ phase are also included in the inset. (b) Temperature dependence of the resonance field, $H_{r}$, for samples $\mathrm{M} 1$ and $\mathrm{M} 3$. The magnetic transitions are indicated by arrows.

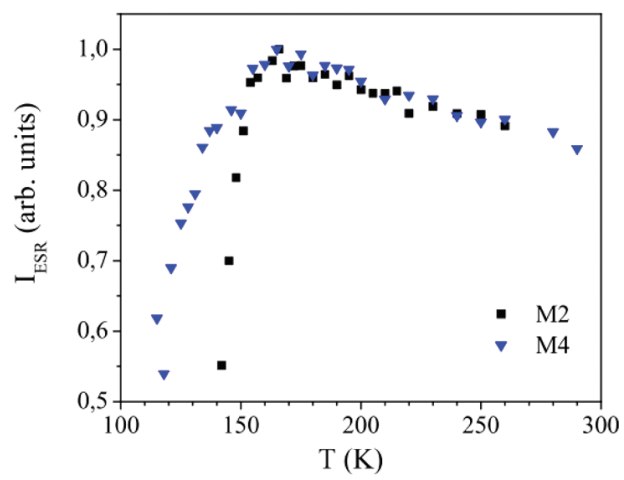

Figure 13. Temperature dependence of the ESR intensity of $\mathrm{MnO}, I_{\mathrm{ESR}}$, for samples M2 and M4.

(92) Tobia, D.; Winkler, E.; Zysler, R. D.; Granada, M.; Troiani, H. E. Phys. Rev. B 2008, 78, 104412 . temperature. As can be observed, the AFM core transition is broad and the onset is located at $T \approx 150 \mathrm{~K}$. This result points out the presence of AFM short-range interaction well above the bulk $T_{\mathrm{N}}$, in agreement with neutron diffraction results. Moreover, the broad $I_{\mathrm{ESR}}$ curve correlates with the tails in the $\mathrm{MnO}$ sublattice magnetization (and the domain fragmentation) observed by neutron diffraction.

In order to analyze the behavior of the shell-narrow ESR line, we show the $\Delta H$ temperature dependence of the $\mathrm{Mn}_{3} \mathrm{O}_{4}$ pure phase in the inset of Figure 12a, where several anomalies as a function of the temperature can be observed. These anomalies correspond to the FiM transition at $T_{\mathrm{C}}=42 \mathrm{~K}$ and the spin reorientation transitions at 39 and $33 \mathrm{~K}^{84}$ These particular $\Delta H$ features are also reproduced by the narrow resonance signal observed in samples M1-M4, which enables us to identify this line as coming from the $\mathrm{Mn}_{3} \mathrm{O}_{4}$ phase. The temperature dependence of $H_{\mathrm{r}}$ also presents anomalies at similar temperatures. As can be observed in Figure $12 \mathrm{~b}, H_{\mathrm{r}}$ shifts toward lower values near $T_{\mathrm{C}}$ and shows anomalies at $T \approx 30$ and $20 \mathrm{~K}$. These features are consistent with the results reported on $\mathrm{Mn}_{3} \mathrm{O}_{4},{ }^{84}$ hence corroborating that the low-temperature features found in the ac and dc susceptibility originate at the shell. The temperature dependence of the resonance field is explained by the presence of an effective anisotropy field $\left(H_{\mathrm{a}}\right)$ below $T_{\mathrm{C}}$, which modifies the resonance condition $h v=g \mu_{\mathrm{B}}\left(H_{\mathrm{r}}+H_{\mathrm{a}}\right){ }^{93}$

It is important to remark that the ground energy state of the $\mathrm{Mn}^{2+}$ ion corresponds to an orbital singlet $L=0$; then the coupling with the lattice is very weak, and as a consequence the ESR line width is narrow and easily observed. On the other hand, the orbital degeneracy of the $\mathrm{Mn}^{3+}$ ion ground state $\left(3 \mathrm{~d}^{4}\right.$, $L=2$ ) is not completely removed and presents important spin-orbit interaction; as a consequence $\mathrm{Mn}^{3+}$ usually does not show an ESR signal. ${ }^{94}$ Therefore, it can be concluded that the narrow ESR line corresponds to the resonance of $\mathrm{Mn}^{2+}$ of the spinel $\mathrm{Mn}_{3} \mathrm{O}_{4}$, while the resonance of $\mathrm{Mn}^{3+}$ could not be detected. This conclusion is supported by several reported results on manganese oxides. ${ }^{95,96}$ In these references, by thermal or chemical treatment, the valence of the manganese ions changes from $\mathrm{Mn}^{3+}$ to $\mathrm{Mn}^{2+}$; as a consequence the ESR signal increases proportionally to the fraction of ions that are reduced from $\mathrm{Mn}^{3+}$ to $\mathrm{Mn}^{2+}$. Moreover, this is also the reason why the $\gamma-\mathrm{Mn}_{2} \mathrm{O}_{3}$ phase, where all the manganese ions are $\mathrm{Mn}^{3+}$, does not present a detectable ESR signal.

From the $I_{\mathrm{ESR}}$ values obtained from the fit for the narrow and broad signals (for $T \gg T_{\mathrm{C}}, T_{\mathrm{N}}$ ), the relative concentrations of $\mathrm{Mn}^{2+}$ ions of the $\mathrm{MnO}$ and $\mathrm{Mn}_{3} \mathrm{O}_{4}$ phases for each sample are calculated. The results are presented in Table 3 . From this quantification it became evident that the overall concentration of the $\mathrm{Mn}_{3} \mathrm{O}_{4}$ diminishes when the nanoparticle size decreases. From the $D_{\text {tot }}$ and $D_{\mathrm{MnO}}$ values obtained by TEM (Table 1 ) for $\mathrm{M} 1-\mathrm{M} 4$, we can estimate the $\mathrm{Mn}_{3} \mathrm{O}_{4}$ relative volume with respect to the total volume of the shell. These data are included in the last column of Table 3 . These results indicate that the surface passivation of the $\mathrm{MnO}$ nanoparticles depends on the size of the particles. Larger particles tend to form $\mathrm{Mn}_{3} \mathrm{O}_{4}$ shells, while the smaller particles have $\gamma-\mathrm{Mn}_{2} \mathrm{O}_{3}$ shells consistent with

(93) Morrish, A. H., The Physical Principles of Magnetism; Wiley-IEEE Press: New York, 2001.

(94) Abragam, A.; Bleaney, B. Electron Paramagnetic Resonance of Transition Ions; Dover Publications: New York, 1986.

(95) Zhang, W.; Yang, Z.; Liu, Y.; Tang, S.; Han, X.; Chen, M. J. Cryst. Growth 2004, 263, 394-399.

(96) Kijlstra, W. S.; Poels, E. K.; Bliek, B. M.; Weckhuysen, B. M.; Schoonheydt, R. A. J. Phys. Chem. B 1997, 101, 309-316. 
Table 3. Relative Concentration of $\mathrm{Mn}^{2+}$ in $\mathrm{MnO}$ and $\mathrm{Mn}_{3} \mathrm{O}_{4}$ Phase Obtained from the ESR Spectra ${ }^{a}$

\begin{tabular}{cllc}
\hline sample & $\mathrm{Mn}^{2+}$ core & $\mathrm{Mn}^{2+}$ shell & $V_{\mathrm{Mn}_{3} \mathrm{O}_{4}} / V_{\text {shell }}$ \\
\hline M1 & $0.82(2)$ & $0.18(2)$ & 1 \\
M2 & $0.985(3)$ & $0.011(3)$ & 0.1 \\
M3 & $0.960(4)$ & $0.032(3)$ & 0.1 \\
M4 & $0.995(1)$ & $0.005(1)$ & 0.005
\end{tabular}

${ }^{a}$ From $D_{\text {tot }}$ and $D_{\mathrm{MnO}}$ obtained by TEM, the shell ratio $V_{\mathrm{Mn}_{3} \mathrm{O}_{4}} / V_{\text {shell }}$ is estimated and included in the last column.

neutron diffraction, EELS, and magnetic results. This fact can be understood from the Catlow and Fender model. ${ }^{36,37,97}$ This model takes into account that the usual defects present in $\mathrm{MnO}$ are Mn vacancies, which are compensated by the oxidation of the manganese ion to $\mathrm{Mn}^{3+}$. Therefore, the larger nanoparticles tend to form $\mathrm{Mn}_{3} \mathrm{O}_{4}$ at the surface. When the nanoparticle size is reduced, the density of defects increases, as was observed by neutron diffraction; consequently, $\gamma-\mathrm{Mn}_{2} \mathrm{O}_{3}$, where all the manganese ions are $\mathrm{Mn}^{3+}$, will be the more stable shell phase.

\section{Conclusions}

In conclusion, we have studied the structural and magnetic properties of bimagnetic core/shell nanoparticles. We found that the nanoparticles present an AFM MnO core and an FiM surface shell. The shell composition depends on the nanoparticle size, the larger nanoparticles presenting mainly $\mathrm{Mn}_{3} \mathrm{O}_{4}$; however, when the size diminishes, the density of defects increases and

(97) Catlow, C. R. A.; Fender, B. E. F. J. Phys. C 1975, 8, 3267-3279. as a consequence $\gamma-\mathrm{Mn}_{2} \mathrm{O}_{3}$ (where all the manganese ions are $\mathrm{Mn}^{3+}$ ) is the more stable shell phase. The systems exhibit exchange coupling between the core and the shell manifested by the exchange bias field and the large coercivity. Although the exchange field is strongly dependent on the magnetic anisotropy of the AFM core, we have observed (from the size dependence of the ESR line width) that while the magnetic anisotropy of the $\mathrm{MnO}$ core shows a smooth increase when the size is reduced, $H_{\mathrm{ex}}$ shows a nonmonotonic behavior. From neutron diffraction we have observed that the Néel temperature of the $\mathrm{MnO}$ core is substantially enhanced and that $\mathrm{MnO}$ presents an enhanced stability above $T_{\mathrm{N}}$. The continuous magnetic phase transition in the AFM core is accompanied by the fragmentation-separation of the magnetic domains in smaller parts.

Acknowledgment. The work was supported by Spanish MICINN grants (Nos. MAT2007-66309-C02 and CSD2006-00012 Consolider-Ingenio 2010), the Catalan DGR (No. 2009-SGR-1292), the Institut Catala de Nanotecnologia, the European Union through the ONDA project (No. FP7-PEOPLE-2009-IRSES-247518), the Russian Foundation for Basic Researches (Grant No. N07-0200608), CONICET Argentina PIP 5250/03, and UNC No. 882/07. We thank the ILL for the provision of neutron beam time.

Supporting Information Available: Text giving the complete ref 88 and supplementary figures. This material is available free of charge via the Internet at http://pubs.acs.org.

JA1021798 